\title{
Observation and Interpretation of Microwave Cloud Signatures over the Arctic Ocean during Winter
}

\author{
GUOSHENG LIU \\ Department of Meteorology, The Florida State University, Tallahassee, Florida \\ Judith A. Curry \\ Program in Atmospheric and Oceanic Sciences, University of Colorado, Boulder, Colorado
}

(Manuscript received 17 December 2001, in final form 22 July 2002)

\section{ABSTRACT}

\begin{abstract}
An analysis of satellite microwave brightness temperatures at $85 \mathrm{GHz}(37 \mathrm{GHz})$ shows that these temperatures sometimes vary by more than $30 \mathrm{~K}(15 \mathrm{~K})$ within 1 or 2 days at a single location over Arctic sea ice. This variation can be seen in horizontal brightness temperature distributions with spatial scales of hundreds of kilometers, as well as in brightness temperature time series observed at a single location. Analysis of satellite observations during winter shows that such brightness temperature warming frequently occurs in the Arctic Ocean, particularly in regions over which low pressure systems often pass. By comparing the observed microwave brightness temperature warming with ground-based measurements of geophysical variables collected during the Surface Heat Budget of the Arctic (SHEBA) experiment and with numerical prediction model analyses from the European Centre for Medium-Range Weather Forecasts (ECMWF), it is found that brightness temperature anomalies are significantly correlated with clouds and precipitation. This finding raises the possibility of using satellite microwave data to estimate cloud liquid water path and precipitation in the Arctic. Factors contributing to the brightness temperature warming were examined, and it was found that the primary contributors to the observed warming were cloud liquid water and surface temperature change.
\end{abstract}

\section{Introduction}

Better knowledge of clouds and their radiative properties in the Arctic is of great importance to our understanding of the regional and global climate (Curry et al. 1996). However, because of the harsh environment, ground-based measurements of the atmosphere and the snow-covered sea ice are sparse in this region. Although there is an ample amount of remotely sensed data from polar-orbiting satellites, the interpretation and quantitative analysis of these data remain a major challenge because of the difficulty in distinguishing between clouds and snow/ice surface using satellite infrared and visible observations (Raschke 1987; Raschke et al. 1992). Because solar radiation is absent during a large portion of the year, satellite observations from visible channels encounter a major drawback in polar regions. Satellite infrared observations are hampered by the fact that frequent atmospheric temperature inversions make it difficult to separate clouds from the snow/ice surface. Consequently, state-of-the-art analyses of cloud prop-

Corresponding author address: Guosheng Liu, Department of Meteorology, The Florida State University, 404 Love Bldg., Tallahassee, FL 32306-4520.

E-mail: liug@met.fsu.edu erties and cloud radiative forcing have the largest errors in the Arctic (Rossow et al. 1993; Ramanathan et al. 1989). In addition, significant differences exist between surface-observed and satellite-inferred climatologies of Arctic clouds (Schweiger and Key 1993; Rossow et al. 1993; Mokhov and Schlesinger 1994) and the disagreement may be partially attributed to the mismatch between satellite and surface measurements. Therefore, improvements in the interpretation of satellite observations are highly desirable for climate research in the Arctic.

A comprehensive review of the characteristics of Arctic clouds and their radiative feedbacks has been given by Curry et al. (1996). The formation mechanisms of Arctic clouds vary with region and the characteristics of the underlying surface. Clouds in the marginal ice zone, particularly during autumn when baroclinic effects are the strongest, are frequently associated with frontal systems and may be convective in nature (Curry et al. 1990). Over the Arctic Ocean, formation of mid- and upper-level clouds are believed to be closely associated with frontal systems (Curry and Herman 1985). The wintertime maximum and summertime minimum of mid- and upper-level clouds is consistent with the association of these clouds with cyclonic activities. Lowlevel clouds form frequently above open leads. 
Detecting the presence of cloud and retrieving cloud microphysical properties in the polar regions has been done by several investigators using visible and infrared techniques that include information on spatial coherence (Ebert 1989; Key 1990; Welch et al. 1992), temporal coherence (Rossow and Garder 1993), and near-infrared channels (Key and Barry 1989; Yamanouchi and Kawaguchi 1992; Raschke et al. 1992). Cloud detection and retrieval algorithms have also developed by Francis (1994), Stubenrauch et al. (1999a,b), and Scott et al. (1999) to assist the retrieval of temperature and moisture profiles in polar regions. An integrated retrieval system was developed by Key (2000) to retrieve multiple microphysical parameters of polar clouds. In an effort to derive surface temperature from infrared radiances, Comiso (1994) developed a statistical method to mask areas covered by clouds, and a technique has been developed to detect and classify clouds by observing reflected sunlight at several different viewing angles (Di Girolamo and Davis 1994). In this study, we investigate the effects of clouds on satellite passive microwave radiances.

Over open-water regions, microwave data have been extensively used for cloud and precipitation studies (e.g., Kummerow et al. 1996; Petty 1994; Smith et al. 1994; Wilheit et al. 1977). In the high latitudes of the North Atlantic, high-frequency microwave data from the Special Sensor Microwave Imager (SSM/I) and the Special Sensor Microwave Water Vapor Sounder have been used to study cloud liquid water and precipitation (both rainfall and snowfall) characteristics by Liu and Curry $(1996,1997)$. They found that during winter, rainfall is observed mainly in regions where storms frequently pass; but snowfall is mostly observed in the regions affected by cold air outbreaks from the continent. They also found that the cloud liquid water path in the region north of $60^{\circ} \mathrm{N}$ is positively correlated to the northward water vapor flux associated with storm movements.

Over sea ice, microwave data have been traditionally used for sea ice concentration and type retrievals (e.g., Cavalieri et al. 1984; Comiso et al. 1991; Gloersen et al. 1992) because of the high microwave emissivity of sea ice in contrast to the low emissivity of open water. Although high-frequency variation of microwave brightness temperatures can be seen in consecutive scenes of satellite images (W. Rossow 1999, personal communication), their magnitude and horizontal extent have not been analyzed quantitatively. Nor are there detailed studies investigating all the possible physical factors that could have caused the variation. Using airborne microwave radiometry measurements, Gloersen et al. (1973) and Gloersen and Campbell (1988) found that microwave brightness temperatures over sea ice in cloudy regions are higher than in clear regions. They interpreted the enhancement to be a result of the increase of surface temperature induced by radiation trapping and excluded the possibility of emission from cloud liquid water, citing the negligible liquid water content. The cloud effect has also been reported in backscattering signatures observed by synthetic aperture radar (Barber and Thomas 1998) over first-year sea ice although this effect is not significant over multiyear sea ice. The increase in backscatter coefficient under cloudy conditions is believed to be due to the temperature-induced changes in thermophysical properties of snow. However, as shown in this paper, surface-based radiometric measurements indicate that there is substantial liquid water in polar clouds even during the winter. The atmosphere, particularly cloud liquid water, may also be a significant contributor to the increase in upwelling microwave energy.

To increase the utility of satellite data in the Arctic, we investigate the cloud and precipitation signatures in satellite microwave measurements over a sea ice background. This study focuses on the magnitude and horizontal extent of these microwave cloud signatures, the possible causes, and the possibility of retrieving cloud and precipitation properties from them. Surface observations of temperature, radiation, cloud, and precipitation obtained during the Surface Heat Budget of the Arctic (SHEBA) experiment are used in conjunction with satellite data to investigate the contributing factors.

\section{Data}

\section{a. SSM/I data}

To identify the cloud signature in microwave observations, satellite data from SSM/I are used. The SSM/ I microwave radiometer aboard a sun-synchronous, polar-orbiting satellite measures brightness temperatures at 19.35-, 22.235-, 37-, and 85.5-GHz frequencies. All measurements are taken at dual polarizations except for $22.235 \mathrm{GHz}$, which has vertical polarization only. Over sea ice, the brightness temperature difference between horizontal and vertical polarizations is only several kelvin at 37 and $85.5 \mathrm{GHz}$; the inclusion of depolarization does not add more information to our analysis. So, in this study, we use vertical polarized brightness temperatures only. The spatial resolution is $15 \mathrm{~km}$ by $13 \mathrm{~km}$ at $85.5 \mathrm{GHz}$ and $37 \mathrm{~km}$ by $29 \mathrm{~km}$ at $37 \mathrm{GHz}$. The swath width is $1395 \mathrm{~km}$ on the earth's surface, and the antenna beam intersects the normal to the earth's surface at an angle of $53^{\circ}$.

\section{b. Ground-based observations at the SHEBA site}

The SHEBA (Perovich et al. 1999) observations were taken from 30 October 1997 through 10 October 1998 and data from four winter months (1 November 199728 February 1998) are used in this study. During the SHEBA experiment, surface and atmospheric parameters were measured in the vicinity of a research ship frozen in the ice that drifted in the Beaufort and Chukchi Seas. In our analysis, we compare the SSM/I brightness temperature with geophysical variables observed at the 
location of the SHEBA observation ship. The surface data used in this study include surface temperature, downward longwave radiation, cloud amount, radar reflectivity, daily snowfall accumulation, and cloud liquid water path.

Longwave radiative fluxes and surface temperature are measured by standard Eppley broadband $(4-50 \mu \mathrm{m})$ radiometers with an uncertainty of $\pm 5 \mathrm{~W} \mathrm{~m}^{-2}$. A surface emissivity of 0.99 was used to convert infrared radiance to surface temperature (Claffey et al. 1999). Comparison of several different methods of determining surface skin temperature suggests an uncertainty in the surface temperature of about $1{ }^{\circ} \mathrm{C}$. Cloud amount was visually observed by a surface observer twice daily. Snowfall collected by a snow gauge was normally inspected once per day at about 1000 local standard time and recorded as daily snowfall accumulation in millimeters (liquid water equivalent). Corrections for evaporation and wind-blowing snow are based on Goodison and Yang (1996). Hourly averaged cloud radar reflectivity data (Intrieri et al. 2002) are used as a proxy of instantaneous snowfall rate. This vertically pointing radar operates at $35 \mathrm{GHz}$ and has an observation range from about 0.1 to $15.1 \mathrm{~km}$ in the vertical. The uncertainty in reflectivity is about $\pm 0.5 \mathrm{dBZ}$, and the minimum detectable threshold is $-49 \mathrm{dBZ}$ at $5-\mathrm{km}$ range. Cloud liquid water path is retrieved using the method of Liljegren (1994) from data of a ground-based dual frequency (23.8 and 31.8 $\mathrm{GHz}$ ) microwave radiometer. The water path retrieved from the microwave radiometer does not include water from ice particles.

\section{Microwave cloud signatures}

The microwave cloud signatures can be identified in satellite microwave SSM/I data from both horizontal distributions of radiance maps over a large area and a time series of radiance variation at a single location. In this section, we show the phenomenology of these signatures in terms of magnitude, spatial scale, and association with weather phenomena.

\section{a. SSM/I signatures over the Arctic basin during winter}

We first examine the microwave signatures over the entire Arctic region observed from 1 December 1992 to 28 February 1993. Most of the polar oceanic region is covered by sea ice during this time of the year except for part of Greenland-Iceland-Norwegian (GIN) Seas where sea surface temperature is warm because of the North Atlantic Drift. In general, the spatial distribution of microwave brightness temperature is largely determined by the surface characteristics. For example, it is colder over multiyear sea ice in the central Arctic and over the snow cover of Greenland, warmer near the marginal sea ice regions. In comparison with the movement of atmospheric synoptic systems, the surface emis- sivity characteristics vary at a much slower rate, as does the mean pattern of the brightness temperature distribution. To extract the signature produced by synoptic weather systems, we use a brightness temperature anomaly defined by the difference between brightness temperature at a given time and its corresponding 15-day mean value at the same location. The reason for using a 15-day mean as background is that the brightness temperature variation associated with a cyclone's passage has a timescale of several days, and using a 15-day mean filters out lower-frequency variations associated with the emissivity change of sea ice surface. A similar approach that subtracts a long-time mean pattern to get cloud and rain signatures over complicated land surfaces has been used by Bauer et al. (2002), Conner and Petty (1998), and Prigent and Rossow (1999).

Examination of the day-to-day brightness temperature anomaly distributions revealed that there were regions with large positive (warm) anomalies frequently observed during the winter months. For convenience, we refer to these regions as hot spots. Figure 1 shows the hot spots observed from 27 December 1992 to 2 January 1993 using brightness temperature anomalies at 85.5 $\mathrm{GHz}$. The figure covers the region north of $70^{\circ} \mathrm{N}$ with the North Pole at the center. Each chart in the figure is a composite of the anomaly of $85.5-\mathrm{GHz}$ brightness temperatures observed during $12 \mathrm{~h}$ centered at 0000 or 1200 UTC. Superimposed are the $850-\mathrm{hPa}$ geopotential heights in solid curves and wind vectors from the European Centre for Medium-Range Weather Forecasts (ECMWF) analysis. Two hot spots can be identified in this sequence of charts. The first can be initially located in Fig. 1a near $70^{\circ} \mathrm{N}, 180^{\circ}$. It moved north, then northeast and was last identified in Fig. $1 \mathrm{~g}$ near $83^{\circ} \mathrm{N}, 110^{\circ} \mathrm{W}$. The second hot spot first appeared in Fig. $1 \mathrm{~g}$ near $72^{\circ} \mathrm{N}$, $15^{\circ} \mathrm{W}$. It moved first northeast, then south, and eventually out of the domain of the chart. Comparing the location of the hot spot with the $850-\mathrm{hPa}$ geopotential height field, it was found that both of the hot spots were in front of the $850-\mathrm{hPa}$ lows and moved with the lows. In front of such low pressure systems, large-scale uplift is usually strong, and results in deep clouds and precipitation.

The brightness temperature variation in the $85.5-\mathrm{GHz}$ imagery associated with the hot spots is substantial. The maximum brightness temperature anomaly near the center of the hot spots in the earlier examples is more than $30 \mathrm{~K}$, while brightness temperature anomalies away from the hot spots decrease to less than $-10 \mathrm{~K}$. Therefore, this signature may be very useful if the causes of the brightness temperature warming are understood. The hot spots can also be seen in images of $37-\mathrm{GHz}$ brightness temperature anomalies although only $85.5-\mathrm{GHz}$ images are shown here. The pattern of the hot spots in $37-$ $\mathrm{GHz}$ images is similar to those in $85.5-\mathrm{GHz}$ images; only the magnitude is about one-half of that at 85.5 $\mathrm{GHz}$. Earlier investigators have also reported the enhancement of microwave brightness temperature under 

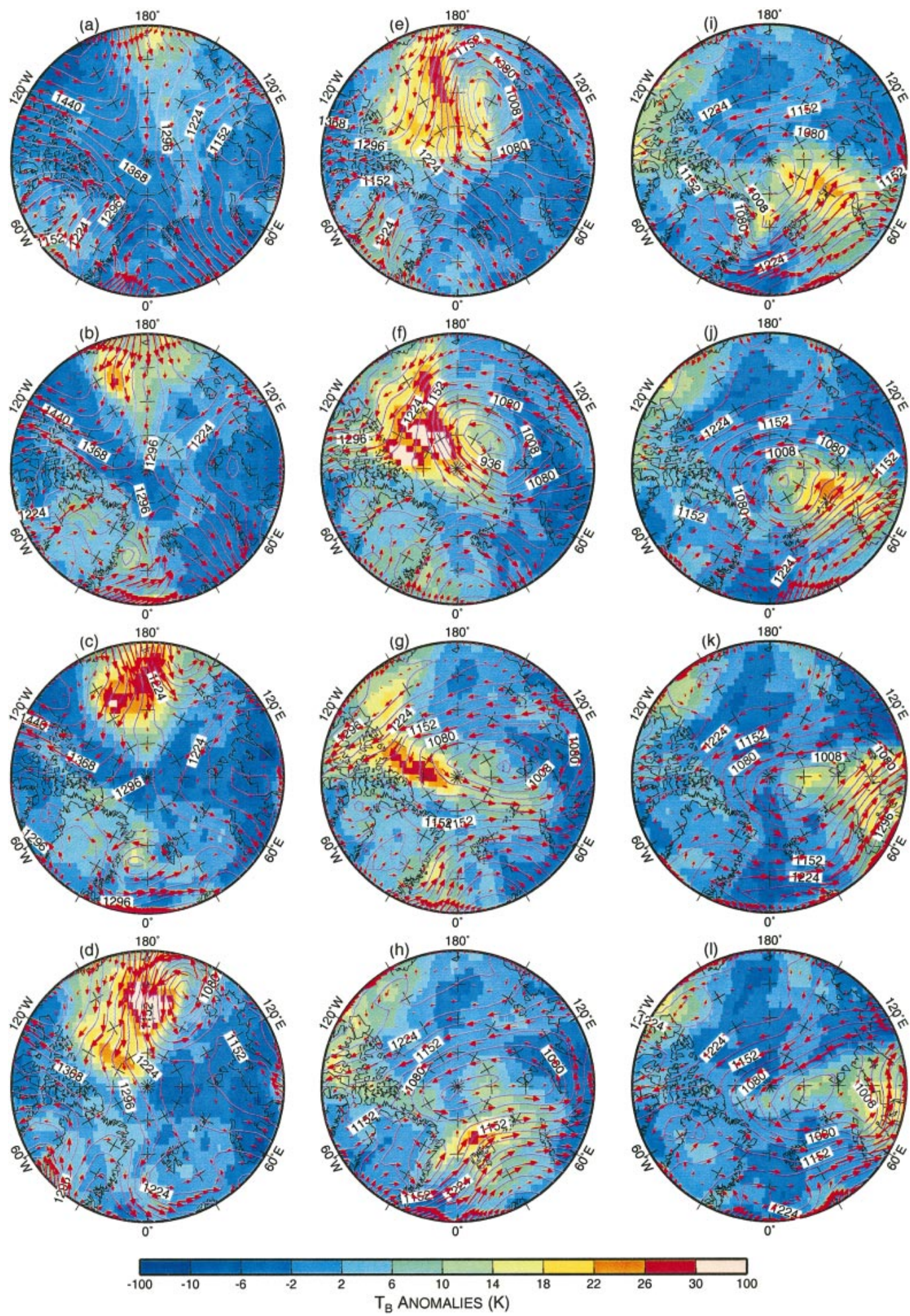

FIG. 1. (a)-(1) A 6-day sequence (twice daily) of the SSM/I 85.5-GHz brightness temperature anomalies from 27 Dec 1992 to 2 Jan 1993 in the Arctic region. Each chart is a composite of satellite observations during $12 \mathrm{~h}$. Superimposed are 850-hPa geopotential heights (solid curves) and wind vectors (arrows) from the ECMWF analysis. The charts cover the region from the North Pole to $70^{\circ} \mathrm{N}$ with the Pole at the center. 


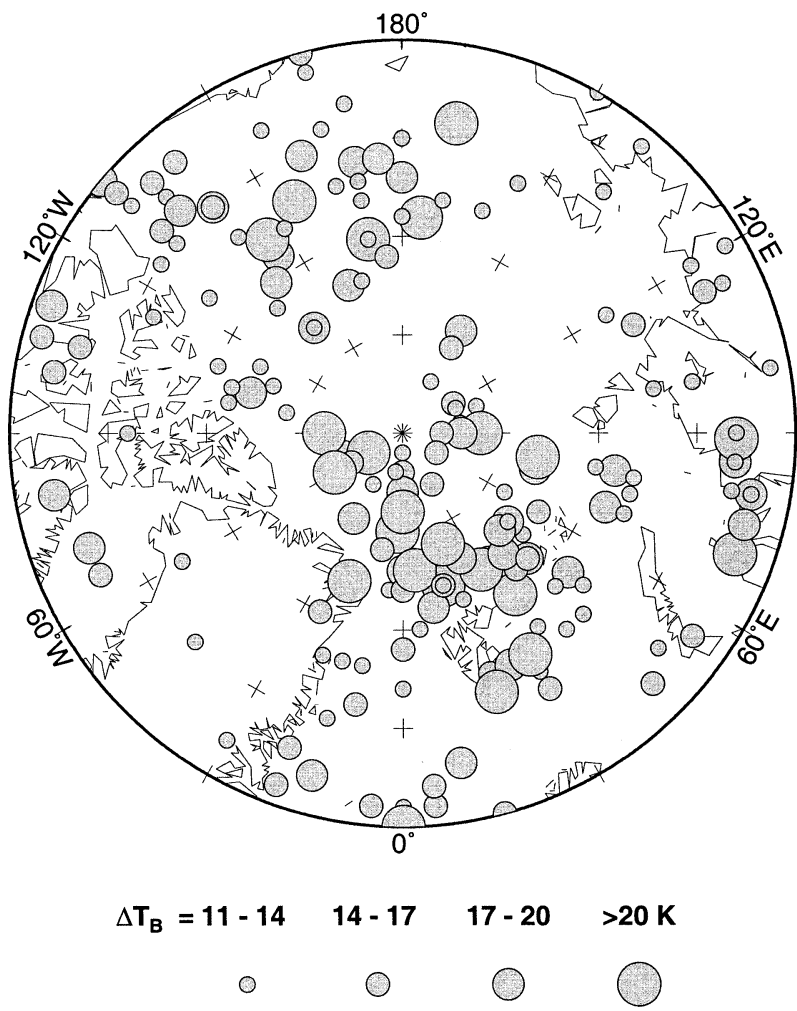

FIG. 2. A survey of hot spots observed during 1 Dec 1992-28 Feb 1993. Only those hot spots with maximum anomalies greater than 10 $\mathrm{K}$ are shown. The chart covers the region from the North Pole to $70^{\circ} \mathrm{N}$ with the Pole at the center.

cloudy conditions. Gloersen et al. (1973) reported that brightness temperatures at $19.35 \mathrm{GHz}$ observed from an airborne radiometer are about $8 \mathrm{~K}$ higher under cloudy conditions than under clear conditions. In a subsequent study, Gloersen and Campbell (1988) concluded that cloudiness helped the melting of sea ice during early summer because of radiation trapping.

The hot spots in microwave satellite data were observed frequently during winter months. Figure 2 shows a survey of the location and intensity of the hot spots observed from 1 December 1992 to 28 February 1993. The intensity is defined by the maximum brightness temperature anomaly $\left(\Delta T_{B}\right)$ at $85.5 \mathrm{GHz}$ within a hot spot. In counting the hot spots, we generated two scenes per day using available SSM/I passes. Each circle in Fig. 2 indicates one hot spot per scene. Only the hot spots whose intensities are greater than $10 \mathrm{~K}$ are shown. We use $10 \mathrm{~K}$ as the minimum threshold because the extent of hot spots with smaller intensities is often not well defined. This survey shows that the majority of the hot spots were observed north of the Beaufort Sea or near the GIN Seas, where storms associated with low pressure systems are active (Serreze et al. 1995; 1997; Thompson and Wallace 1998; Walsh and Portis 1999). This further indicates that the hot spots are directly associated with low pressure systems, and that the number and intensity of the hot spots are an indication of the frequency and intensity of storms in the Arctic region.

\section{b. SSM/I signatures at the SHEBA site during winter}

In this section, we examine how the SSM/I 85.5-GHz brightness temperatures sampled at the location of the SHEBA ship site responded to various variables observed at the surface using data for 1 November 199728 February 1998. The surface-observed variables include temperatures at the snow surface $\left(T_{0}\right)$ and snowsea ice interface ( $\left.T_{\text {ice }}\right)$, downward longwave (LW) radiation, cloud amount, daily snowfall accumulation, hourly averaged cloud radar reflectivity at 300-m altitude, and hourly averaged liquid water path (LWP). All these surface data are obtained from the SHEBA data archive. Time series of these variables are shown in Fig. 3. The $85.5-\mathrm{GHz}$ brightness temperatures shown in the figure are the average of those within $0.5^{\circ}$ (lat-lon) of the SHEBA ship site. A value of less than 0 in the cloud amount chart indicates missing data.

The $85.5-\mathrm{GHz}$ brightness temperature at the SHEBA site is seen to vary by tens of kelvins within several days. Corresponding to these brightness temperature changes, surface-observed variables have similar variations, except for the snow-ice interface temperature, $T_{\text {ice }}$. The correspondence is particularly evident for surface temperature, longwave radiation, and radar reflectivity. Because of missing data, the cloud amount observation missed several snowfall events (e.g., day 35, and from day 86 to day 90 ). There are no liquid water path observations before day 34 . Otherwise, the peaks correspond well with the increases in $85.5-\mathrm{GHz}$ brightness temperature, as well as with other surface measurements. On several occasions, the retrieved liquid water path became as large as several hundred grams per square meter. For almost all snowfall events shown in Figs. $3 \mathrm{e}$ and $3 \mathrm{j}$, we find an increase in brightness temperature in Figs. $3 \mathrm{a}$ and $3 \mathrm{f}$. There is sometimes a time lag between the increase in $85.5-\mathrm{GHz}$ brightness temperature and the daily snowfall accumulation. For example, on day 35 a heavy snowfall accumulation is recorded, but the $85.5-\mathrm{GHz}$ brightness temperature did not show a large increase until day 36; neither do the other variables. The reason for this delay is not clear.

We further examine the correlation between brightness temperature anomaly and surface-measured variables using scatterplots and correlation coefficients as shown in Fig. 4. Similar to the brightness temperature anomaly, the anomalies for downward longwave radiation and surface temperature are also calculated by the difference between an instantaneous value and its 15day mean. Hourly data are used in the charts for longwave radiation, surface temperature, liquid water path, and radar reflectivity, and daily-averaged data are used in the charts for daily snowfall accumulation. All surface-observed variables shown in the scatterplot are significantly correlated with brightness temperature anom- 

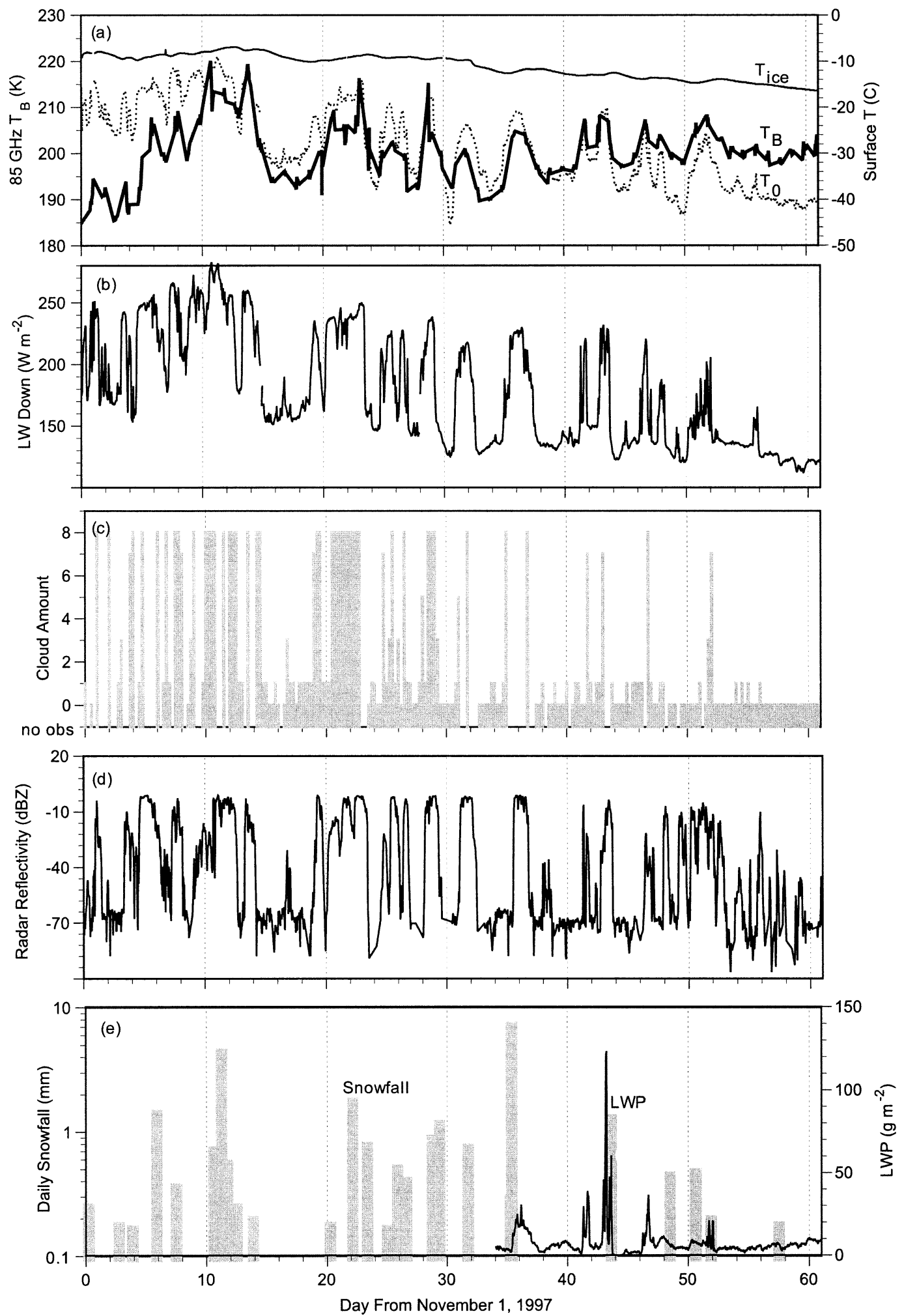

FIG. 3. Times series of the SSM/I 85.5-GHz brightness temperature and ground-based measurements at the SHEBA ship site: (a)-(e) the 60-day period starting 1 Nov 1997 and (f)-(j) day 61-28 Feb 1998. (a), (f) 85.5-GHz $T_{B}$, surface (skin) temperature $\left(T_{0}\right)$ and snow-sea ice interface temperature $\left(T_{\text {ice }}\right),(\mathrm{b}),(\mathrm{g})$ downward longwave radiation, $(\mathrm{c}),(\mathrm{h})$ cloud amount observed by a surface observer, (d), (i) hourly averaged radar reflectivity at 300-m altitude, (e), (j) daily snowfall accumulation observed by a surface observer and liquid water path (LWP) retrieved from surface-based microwave radiometer. 

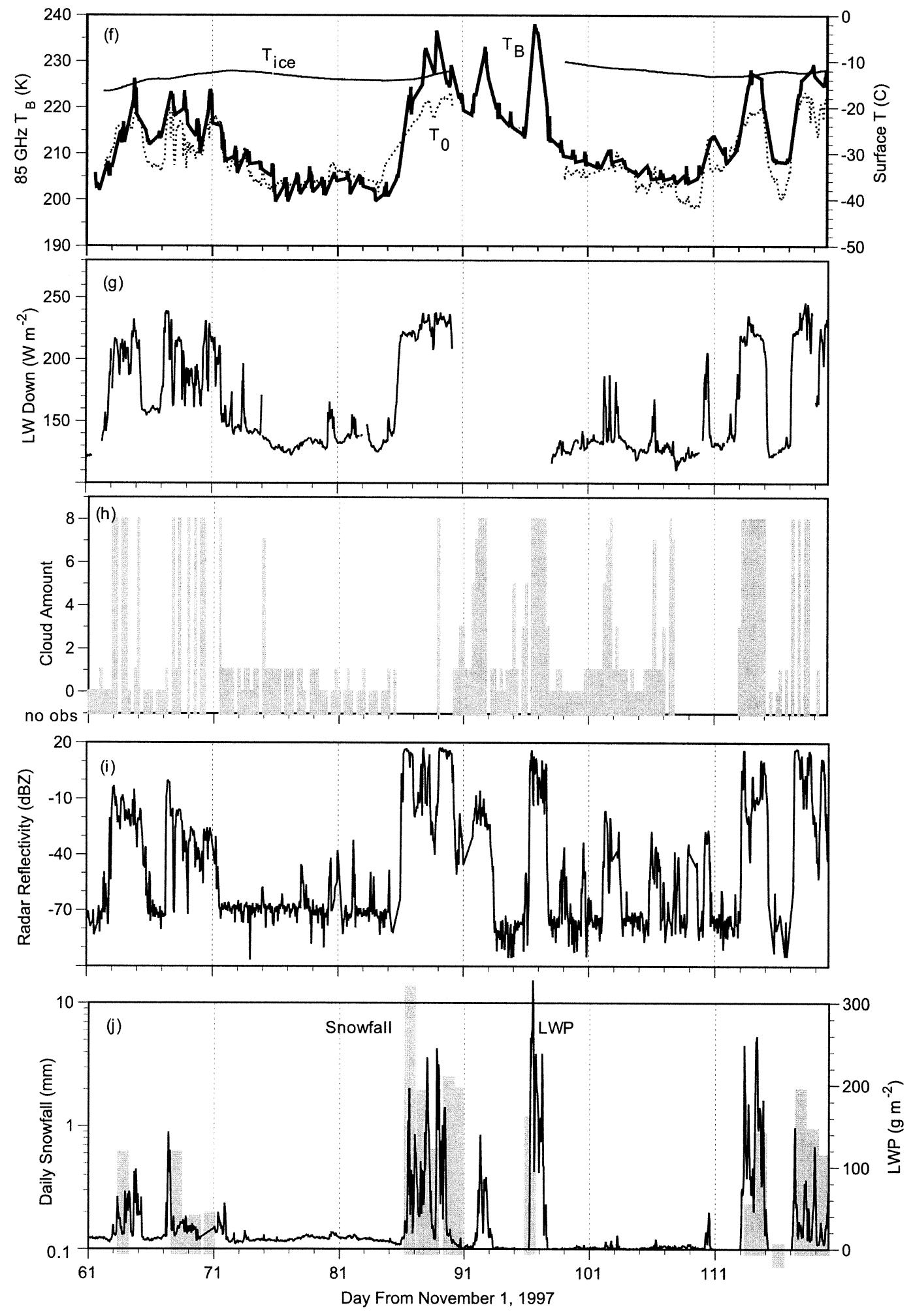

FIG. 3. (Continued) 

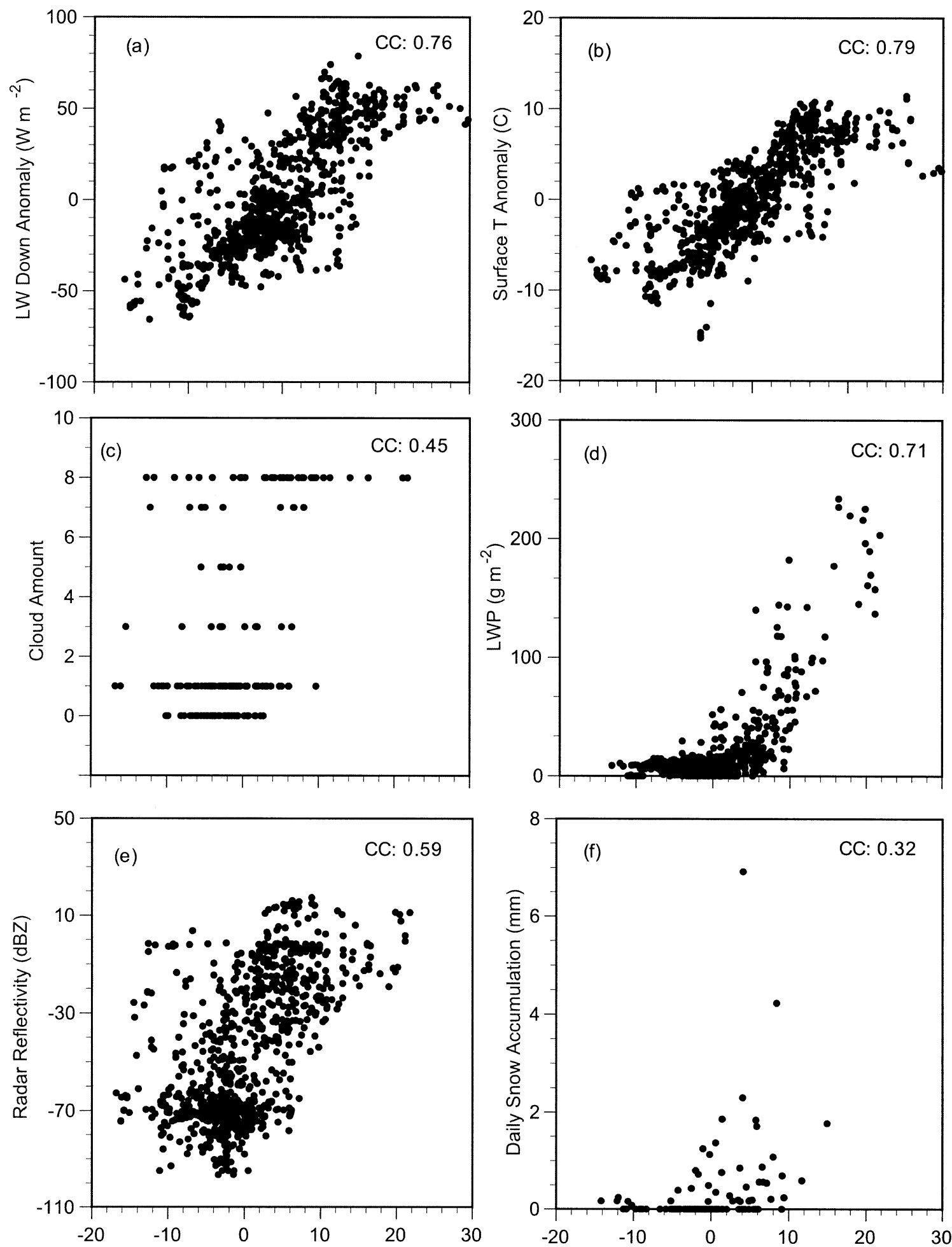

$85 \mathrm{GHz}$ Brightness Temperature Anomaly (K)

FIG. 4. Scatterplot of $85.5-\mathrm{GHz}$ brightness temperature anomalies $\left(\Delta T_{B}\right)$ vs surface-based observations at the SHEBA ship site from 1 Nov 1997 through 28 Feb 1998: (a) $\Delta T_{B}$ vs downward longwave radiation anomaly, (b) $\Delta T_{B}$ vs surface skin temperature anomaly, (c) $\Delta T_{B}$ vs cloud amount, (d) $\Delta T_{B}$ vs liquid water path, (e) $\Delta T_{B}$ vs radar reflectivity at $300 \mathrm{~m}$, and (f) $\Delta T_{B}$ vs daily snowfall accumulation. 
TABLE 1. Cross-correlation coefficients among observations near the SHEBA site $\left(\Delta T_{\mathrm{B} 85}: 85-\mathrm{GHz}\right.$ brightness temperature anomaly; $\Delta \mathrm{LW}_{\text {down }}$ : downward longwave radiation anomaly; $\Delta T_{\text {surf }}$ : surface temperature anomaly; CldAmt: cloud amount; LWP: liquid water path; RadarRef: radar reflectivity at $300 \mathrm{~m}$; SnowAcc: daily snow accumulation).

\begin{tabular}{|c|c|c|c|c|c|c|c|}
\hline & $\Delta T_{\mathrm{B} 85}$ & $\Delta \mathrm{LW}_{\text {down }}$ & $\Delta T_{\text {surf }}$ & CldAmt & LWP & RadarRef & SnowAcc \\
\hline$\overline{\Delta T_{\mathrm{B} 85}}$ & 1 & 0.76 & 0.79 & 0.45 & 0.71 & 0.59 & 0.32 \\
\hline$\Delta \mathrm{LW}_{\text {down }}$ & & 1 & 0.91 & 0.74 & 0.54 & 0.75 & 0.28 \\
\hline$\Delta T_{\text {surf }}$ & & & 1 & 0.64 & 0.44 & 0.69 & 0.22 \\
\hline CldAmt & & & & 1 & 0.57 & 0.72 & 0.27 \\
\hline LWP & & & & & 1 & 0.55 & 0.29 \\
\hline RadarRef & & & & & & 1 & 0.37 \\
\hline SnowAcc & & & & & & & 1 \\
\hline
\end{tabular}

aly at a $99 \%$ confidence level, although the correlation coefficient between brightness temperature anomaly and daily snowfall accumulation is small (0.32). It should be noted that daily snowfall accumulation accounts for snow that fell at any time during a day, while the satellite overpasses the observation site only two to four times during a day. The mismatch of sampling time between the two observations may have contributed to the low correlation. If the radar reflectivity at $300 \mathrm{~m}$ is used as a proxy of instantaneous snowfall, we found that its correlation with the brightness temperature anomaly is much better (0.59). This is an important finding because it opens the possibility of using satellite microwave data to estimate snowfall in the Arctic, which is a decisive parameter in the Arctic hydrological balance and the least measured. In Table 1, the cross correlations among the observed parameters are listed. It is seen that radar reflectivity also has high correlations with surface temperature and downward longwave radiation.

Under cloudy conditions, downward longwave radiation increases, which in turn increases snow surface temperature (Overland and Guest 1991; Curry et al. 1997). Snow surface temperature increases to balance

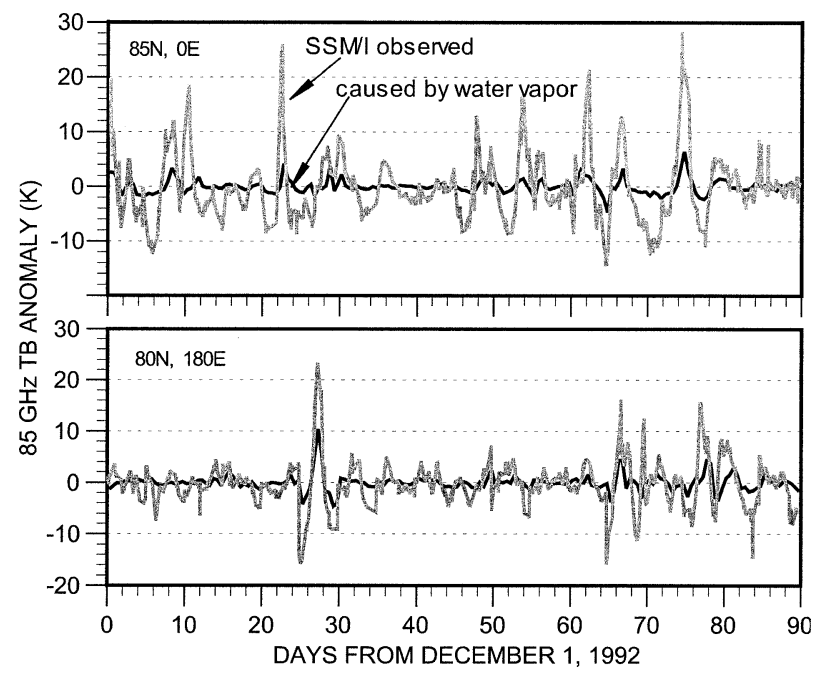

FIG. 5. Time series of SSM/I $85.5-\mathrm{GHz}$ brightness temperature anomalies at (top) $\left(85^{\circ} \mathrm{N}, 0^{\circ}\right)$ and (bottom) $\left(85^{\circ} \mathrm{N}, 180^{\circ}\right)$ from $1 \mathrm{Dec}$ 1992 to 28 Feb 1993. Dark line: observed. Light line: simulated by only varying water vapor amount based on the ECMWF analysis. the increased downward longwave radiation in the quasi-radiative-equilibrium system, and returns to the original surface temperature value (the local minima in the time series of Figs. 3a and 3f) once the sky clears. The good correlation between SSM/I 85.5-GHz brightness temperature and surface-measured parameters at the SHEBA site indicates that the short-term variations in brightness temperature are caused by cloud systems and confirms our conclusion that the hot spots in these polar regions result from clouds associated with synoptic systems.

\section{Analysis of factors contributing to the hot spots}

As shown in the previous section, the observed increase in microwave brightness temperature is coincident with the increase of cloudiness and surface temperature. Although the increases in surface temperature are a result of the cloudiness, the radiance received by a microwave radiometer on a satellite may have been affected by changes both in the atmosphere and at the surface. In this section, we examine factors that could have contributed to the microwave brightness temperature increase, namely, water vapor, cloud liquid water, cloud ice, falling snow, surface temperature, and surface emissivity.

\section{a. Water vapor}

In the polar region during winter, water vapor amount is low, and precipitable water is typically less than 10 $\mathrm{kg} \mathrm{m}^{-2}$. Our model calculations suggest that this small water vapor amount only contributes a few degrees $(\mathrm{K})$ to the $85.5-\mathrm{GHz}$ microwave brightness temperature. Figure 5 shows the time series of the $85.5-\mathrm{GHz}$ brightness temperature anomaly $\left(\Delta T_{\mathrm{B} 85}\right)$ averaged inside a circle of $2.5^{\circ}$ (lat-lon) in diameter centered at $85^{\circ} \mathrm{N}, 0^{\circ}$, and $85^{\circ} \mathrm{N}, 180^{\circ}$ during the three winter months starting 1 December 1992. In the same figure, the radiative transfer model-simulated $\Delta T_{\mathrm{B} 85}$ by assuming that only water vapor varies is also plotted. The radiative transfer model of Liu (1998) is used in the calculations. The surface emissivity model is adapted from the empirical function by Grody (1993) for multiyear sea ice, which results in an emissivity value of $\sim 0.7$, similar to that determined by airborne radiometer measurements (Haggerty and 


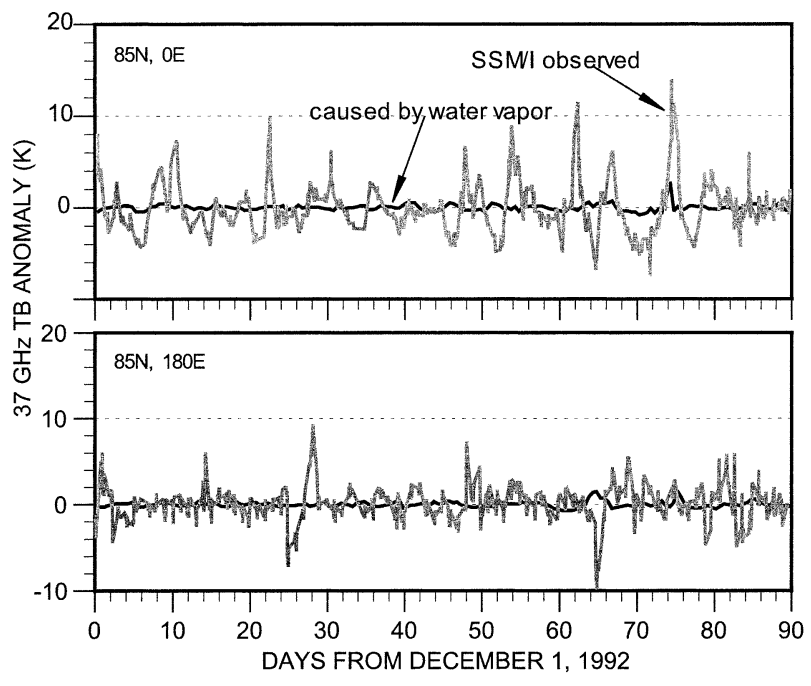

FIG. 6. Same as in Fig. 5 but for $37 \mathrm{GHz}$.

Curry 2001). The water vapor profiles are from ECMWF analyses, which have $2.5^{\circ}$ spatial and 12-h temporal resolution. It is seen that the observed $\Delta T_{\mathrm{B} 85}$ has a much larger magnitude than the water vapor-induced $\Delta T_{\mathrm{B} 85}$. While the maximum peak-to-peak difference in the observed $\Delta T_{\mathrm{B} 85} \mathrm{~s}$ exceeds $30 \mathrm{~K}$ in several cases, the difference caused by water vapor variation is smaller than $10 \mathrm{~K}$ except for one occasion on day 27 at $85^{\circ} \mathrm{N}, 180^{\circ}$, which is close to $10 \mathrm{~K}$. More generally, the $\Delta T_{\mathrm{B} 85}$ variance caused by water vapor variation is less than $5 \mathrm{~K}$. Therefore, the water vapor contribution can only explain a fraction of the magnitude in brightness temperature variation.

Similarly, the time series of brightness temperature anomaly at $37 \mathrm{GHz}, \Delta T_{\mathrm{B} 37}$, is shown in Fig. 6. The microwave signatures at $37 \mathrm{GHz}$ are quite similar to those at $85.5 \mathrm{GHz}$ except for $\Delta T_{\mathrm{B} 37}$ being about onehalf of the magnitude of $\Delta T_{\mathrm{B} 85}$. The variation of water vapor amount has little effect on $\Delta T_{\mathrm{B} 37}: 1$ or $2 \mathrm{~K}$ at most as compared with the maximum peak-to-peak difference of $20 \mathrm{~K}$ in observed $\Delta T_{\mathrm{B} 37}$.

\section{b. Cloud liquid water}

As shown in Fig. 3, surface-based measurements suggest a considerable amount of cloud liquid water in polar clouds even during winter when the temperature is mostly colder than $-20^{\circ} \mathrm{C}$ throughout the atmosphere. Temperature inversions typically are present in the lower atmosphere, with the ice surface temperature colder than the lower atmosphere. Using an Arctic wintertime temperature and humidity profile from the ECMWF analysis, the variation of microwave brightness temperature with cloud liquid water path was simulated. The layer of cloud liquid water is assumed to be in the warm layer of the inversion. Again, the surface emissivity for multiyear sea ice is based on Grody (1993), which is $\sim 0.7$ for $85.5 \mathrm{GHz}$ and $\sim 0.75$ for $37 \mathrm{GHz}$. Figure 7 shows

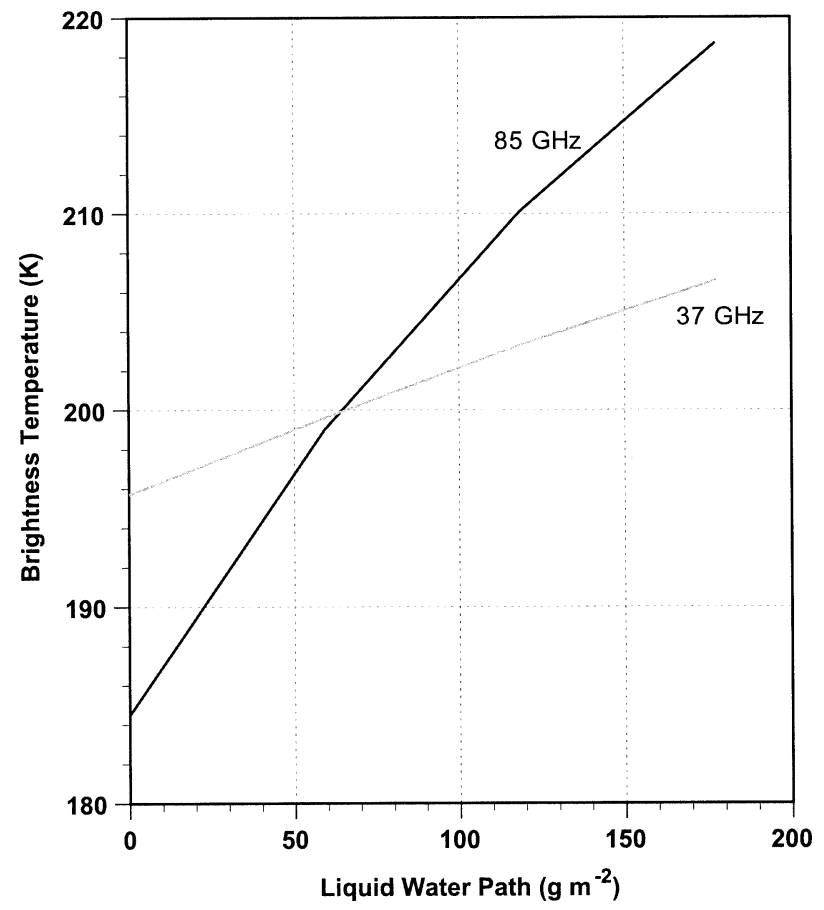

FIG. 7. Radiative transfer model-simulated relationships between brightness temperature and liquid water path for 37 and $85.5 \mathrm{GHz}$.

the simulated results of brightness temperature versus liquid water path. It is shown that cloud liquid water can increase the microwave radiation significantly. For example, a liquid water path of $50 \mathrm{~g} \mathrm{~m}^{-2}$ can increase brightness temperature at $85.5 \mathrm{GHz}$ by $11 \mathrm{~K}$ and at 37 $\mathrm{GHz}$ by $3 \mathrm{~K}$.

Since there is no liquid precipitation during the Arctic winter, the liquid water path reflects only cloud liquid water amount. A $50(100) \mathrm{g} \mathrm{m}^{-2}$ liquid water path is equivalent to a liquid water layer of $0.1 \mathrm{~g} \mathrm{~m}^{-3}$ in cloud water content and $0.5(1.0) \mathrm{km}$ in cloud depth. These numbers are typical for low-latitude marine stratus (e.g., Zuidema and Hartmann 1995). In Fig. 3, the groundbased microwave radiometer measurements indicate that the hourly averaged LWP can be as high as several hundred grams per square meter at the SHEBA site. Although the accuracy of the LWP retrievals needs further investigation, the large value of LWP suggests the importance of the cloud liquid water contribution to the microwave brightness temperature anomaly. Given the high correlation coefficient $(0.71)$ between brightness temperature anomaly and liquid water path as shown in Fig. 4, it is plausible that the cloud liquid water contributes at least partially to the brightness temperature variation. This cloud liquid water effect has not been considered by previous investigators (Gloersen et al. 1973).

\section{c. Cloud ice and snowfall}

It is common knowledge that low pressure storms in high latitudes are associated with cloud ice and snowfall. 
Scattering by snowflakes may become strong enough to alter the upwelling microwave radiance, especially at 85.5 GHz. However, ice scattering acts to lower the upwelling brightness temperature instead of increasing it. Our estimate using the radiative transfer model shows that an ice water path of $500 \mathrm{~g} \mathrm{~m}^{-2}$ in cloud ice/snow reduces the $85.5-\mathrm{GHz}$ brightness temperature by about 5 K. A recent study by Bennartz and Petty (2001) indicated that the brightness temperature depression could be as large as $20 \mathrm{~K}$. In any case, cloud ice and snowfall decrease the upwelling microwave radiation and cannot explain the brightness temperature increase. The significant correlation between brightness temperature anomaly and near-surface radar reflectivity-daily snowfall accumulation does not directly result from falling snow. Rather, it is an indirect result from the fact that both brightness temperature and snowfall vary with cloudiness.

\section{d. Surface temperature}

As shown in the previous section, snow surface temperature also increases substantially with cloudiness, which has also been reported by previous investigators (Gloersen et al. 1973; Overland and Guest 1991; Curry et al. 1997; Barber and Thomas 1998). The magnitude of this surface temperature increase is as much as 15$20 \mathrm{~K}$, comparable to the observed brightness temperature increase at $85.5 \mathrm{GHz}$. If the snow surface were a blackbody at microwave wavelengths, the microwave brightness temperature increase could have been readily explained by the surface temperature effect. Gloersen et al. (1973) and Gloersen and Campbell (1988) concluded that the microwave brightness temperature enhancement is indeed due to this phenomenon.

However, accumulated snow on sea ice is not a blackbody in the microwave region, especially if the snow is dry, as it is in midwinter. Although there may be significant emission from the snow layer at $85.5 \mathrm{GHz}$, the major effect of dry snow on microwave emission at frequencies lower than $37 \mathrm{GHz}$ is scattering, that is, reducing upward radiation from the underlying sea ice (Ulaby et al. 1981). Therefore, the increase in snow surface temperature can only partially be converted to the increase in brightness temperature because the emissivity of the snow layer may be well below 1. Additionally, the maximum increase in surface temperature due to downward longwave radiation occurs near the skin layer of the surface, while the penetration depth of microwaves is much larger. Table 2 shows the penetration depth for 85.5 and $37 \mathrm{GHz}$ over sea ice and dry snow cover, calculated following Ulaby et al. (1981) without including scattering effects. Over dry snow, the penetration depth exceeds $25 \mathrm{~cm}$ at $85.5 \mathrm{GHz}$ and more than $100 \mathrm{~cm}$ at $37 \mathrm{GHz}$. Therefore, even if the snow layer emits significant amount of microwave energy, its effective temperature should be the weighted average of temperatures within a layer tens of centimeters thick
TABle 2. Penetration depth (cm).

\begin{tabular}{lcccrrr}
\hline \hline & \multicolumn{2}{c}{$85.5 \mathrm{GHz}$} & & \multicolumn{2}{c}{$37 \mathrm{GHz}$} \\
\cline { 2 - 3 } \cline { 5 - 6 } \cline { 5 - 6 } & $-15^{\circ} \mathrm{C}$ & $-30^{\circ} \mathrm{C}$ & & $-15^{\circ} \mathrm{C}$ & $-30^{\circ} \mathrm{C}$ \\
\hline Dry snow & 27 & 37 & & 108 & 153 \\
Multiyear sea ice & 5 & 10 & & 10 & 23 \\
First-year sea ice & 1.5 & 4 & & 2 & 6 \\
\hline
\end{tabular}

(weighted more heavily by temperatures closer to the surface). Because the temperature deep within the snow is less affected by cloudiness (see $T_{\text {ice }}$ in Fig. 3), particularly over multiyear sea ice (Barber and Thomas 1998), the variation of brightness temperature caused by the temperature change of the snow layer should be smaller than the change of the snow surface temperature itself. It should be mentioned here that the penetration depth at $85.5 \mathrm{GHz}$ calculated in this study contains uncertainties because the dielectric constant of snow is essentially unknown at this frequency but is extrapolated from lower frequencies.

In conclusion, although snow surface temperature increases at a similar magnitude to that of brightness temperature, the $<1$ emissivity and the large penetration depth for the dry snow layer do not seem to support the idea that increases in microwave brightness temperature are solely caused by the increases in snow surface temperature. The surface temperature effect may, however, be one of the important contributors to the hot spots given the good correlation between microwave brightness temperature and snow surface temperature as shown in Fig. 4.

\section{e. Surface emissivity}

Storms affect surface emissivity characteristics in the following three ways: 1) providing fresh snow on the ground, 2) changing surface roughness by blowing snow, and 3) creating open leads by wind stress. Open leads change the upward microwave radiation because of the different temperature and emissivity between leads and snow-covered ice. However, the area fraction of leads in Arctic winter rarely exceeds $0.5 \%$ (Curry and Webster 1999). Assuming the open leads to have a temperature of $273 \mathrm{~K}$ and an emissivity of 0.6 (typical for water at $85.5 \mathrm{GHz}$ ) surrounded by multiyear sea ice with temperature of $230 \mathrm{~K}$ and emissivity of 0.7 , the presence of leads raises brightness temperature by less than $1 \mathrm{~K}$ if its area fraction is less than $1 \%$ within a satellite footprint. Therefore, the open leads' contribution is not significant for the winter season although it becomes important during melting seasons when the open-water fraction increases dramatically. Strong wind makes snow layers thicker in some areas and thinner in other areas. Where the snow layer is very thick, the observed radiation comes primarily from the snow. Where it is thin, the radiation may come primarily from the sea ice that may be initially somewhat warmer than 
TABLE 3. Summary of possible factors contributing to hot spots.

\begin{tabular}{|c|c|c|c|}
\hline Factors & Phenomenology & $\begin{array}{l}\text { Estimated maximum } \\
\text { contribution }\end{array}$ & $\begin{array}{c}\text { Degree of } \\
\text { importance* }\end{array}$ \\
\hline Water vapor & Increase atmospheric emission & $\sim 5 \mathrm{~K}$ & $\mathrm{SC}$ \\
\hline Cloud liquid water & Increase cloud emission & $\sim 10 \mathrm{~K}$ & $\mathrm{PC}$ \\
\hline Cloud ice snow & $\begin{array}{l}\text { Decrease brightness temperature through } \\
\text { scattering }\end{array}$ & Negative & $\mathrm{NI}$ \\
\hline Surface temperature & $\begin{array}{l}\text { Increase surface temperature due to down- } \\
\text { ward longwave radiation }\end{array}$ & $\sim 10 \mathrm{~K}$ & PC \\
\hline Open leads & $\begin{array}{l}\text { Increase open water area, but fraction is } \\
\text { small during winter }\end{array}$ & $<2 \mathrm{~K}$ & NI \\
\hline Surface roughness & Variation in snow cover depth & $<5 \mathrm{~K} ?$ & $\mathrm{NI} / \mathrm{SC}$ \\
\hline
\end{tabular}

* Symbol PC $=$ primary contributor, $\mathrm{SC}=$ secondary contributor, and $\mathrm{NI}=$ not important.

the snow-covered surface (see Fig. 3). It is unclear how big this wind effect is on brightness temperature. Future ground-based in situ studies are necessary for a more quantitative assessment. In addition, analyzing coincident synthetic aperture radar and SSM/I data for better understanding of the surface roughness and open leads effects is also desirable in future studies.

\section{f. Summary of the affecting factors}

The relative importance of the factors discussed above is summarized in Table 3. Of the possible causes of the microwave hot spots, cloud liquid water and surface temperature are the most important, although no one factor seems to dominate. We hypothesize that the increases in microwave brightness temperatures associated with cyclonic storms are largely a result of a combination of these two factors. An interesting point is the suggestion of a large amount of cloud liquid water in the cold environment. If one-third of a $30 \mathrm{~K}$ increase in $85.5-\mathrm{GHz}$ brightness temperature is caused by cloud liquid water, the liquid water path should be approximately $50 \mathrm{~g} \mathrm{~m}^{-2}$, which is considered an extremely large value given the cold temperatures during the Arctic winter. The presence of significant liquid water in Arctic winter clouds is further supported by ground-based microwave observations at the SHEBA ship site (Fig. 3), which suggests that hourly averaged liquid water path can be as large as a few hundred grams per square meter.

\section{Conclusions}

In investigating the satellite microwave signatures over snow-covered sea ice in the Arctic region, it is found that brightness temperatures at $85 \mathrm{GHz}$ vary by more than $30 \mathrm{~K}$ over 1 or 2 days. This variation can be seen in horizontal brightness temperature distributions over a spatial scale of hundreds of kilometers, as well as in the brightness temperature time series observed at a single location at the SHEBA ship site. Analysis of satellite observations from December 1992 through February 1993 showed that such brightness temperature warming frequently occurs in the Arctic Ocean, particularly over the regions where low pressure systems often pass. By comparing the microwave brightness temperatures with surface observations and ECMWF analyses, it is found that the warming is associated with clouds and precipitation formed by low pressure systems. This finding leads us to suggest the use of satellite microwave signature to assess clouds, snowfall, and storm activity in the Arctic region.

Factors contributing to the brightness temperature increase have been examined, including water vapor, cloud liquid water, cloud ice/snow, and surface temperature and emissivity. While the microwave brightness temperature warming is associated with cloudiness, the extra radiance that causes the warming comes from both the atmosphere and the surface. The atmospheric effect is due to cloud liquid water emission and the surface effect arises from the cloud-induced longwave heating to the snow surface. It is concluded that cloud liquid water and an increase in surface temperature are the main contributors to the observed microwave brightness temperature warming. One of the interesting implications of the large brightness temperature increase is the indication that a significant amount of cloud liquid water exists in the polar clouds even during winter. A rough estimate suggests that it could reach $50 \mathrm{~g} \mathrm{~m}^{-2}$ or higher at satellite pixel scale $(\sim 15 \mathrm{~km})$ in some cases. Ground-based radiometer observations also indicate that the liquid water path can be as large as several hundred grams per square meter, which further emphasizes the importance of cloud liquid water in contributing to the microwave brightness temperature increases.

The hot spots are clearly associated with synoptic storms. Therefore, by utilizing the microwave signature, it is possible to study the track, frequency of occurrence, cloud liquid water path, and precipitation of storms in the Arctic region, which is of great importance in Arctic climate research (Maslanik et al. 1995). Additionally, storms originating at low latitudes transport water vapor and heat to the Arctic region (Overland and Guest 1991; Groves 1999; Liu and Curry 1996; Serreze et al. 1995). Studies on the frequency and movement of storms could assist in determining energy and water budgets in the polar region. Furthermore, the significant correlation between brightness temperature anomaly and near-surface 
radar reflectivity-daily snowfall accumulation suggests the potential use of microwave signature to estimate snow precipitation over the polar region, which is largely unknown over the basin scale.

Acknowledgments. Surface data at the SHEBA ship site were provided by the SHEBA project. SSM/I brightness temperature data were provided by NASA Marshall Space Flight Center. The authors are grateful to Dr. H. Cooper for his constructive comments and his assistance in editing the manuscript. Comments from three anonymous reviewers were helpful in improving the presentation of our results. This study has been supported by NASA Grants NAG5-8647 and NAG5-11889, and NSF Grant ATM-0002860. Judith Curry's participation was supported by the NASA FIRE project.

\section{REFERENCES}

Barber, D. G., and A. Thomas, 1998: The influence of cloud cover on the radiation budget, physical properties, and microwave scattering coefficient $\left(\sigma^{0}\right)$ of the first-year and multiyear sea ice. IEEE Trans. Geosci. Remote Sens., 36, 38-50.

Bauer, P., D. Burose, and J. Schulz, 2002: Rain detection over land surfaces using passive microwave satellite data. Meteor. Z., 11, 37-48.

Bennartz, R., and G. W. Petty, 2001: The sensitivity of passive microwave radiances in precipitating clouds to ice particle size distributions. J. Appl. Meteor., 40, 345-364.

Cavalieri, D. J., P. Gloersen, and W. J. Campbell, 1984: Determination of sea ice parameters with the Nimbus-7 SMMR. J. Geophys. Res., 89, 5355-5369.

Claffey, K. J., E. L Andreas, D. K. Perovich, C. W. Fairall, P. S. Guest, and P. O. G. Persson, 1999: Surface temperature measurements at SHEBA. Preprints, Fifth Conf. on Polar Meteorology and Oceanography, Dallas, TX, Amer. Meteor. Soc., 327 332 .

Comiso, J. C., 1994: Surface temperatures in the polar regions from Nimbus 7 temperature humidity infrared radiometer. J. Geophys. Res., 99, 5181-5200.

— , P. Wadhams, W. Krabill, R. Swift, J. Crawford, and W. Turker, 1991: Top/bottom multisensor remote sensing of Arctic sea ice. J. Geophys. Res., 96, 2693-2711.

Conner, M. D., and G. W. Petty, 1998: Validation and intercomparison of SSM/I rain rate retrieval methods over the continental United States. J. Appl. Meteor., 37, 679-700.

Curry, J. A., and G. F. Herman, 1985: Infrared radiative properties of Arctic stratus clouds. J. Climate Appl. Meteor., 24, 525-538. - and P. J. Webster, 1999: Thermodynamics of Atmospheres and Oceans. Academic Press, 471 pp.

- C. D. Ardeel, and L. Tian, 1990: Liquid water content and precipitation characteristics of stratiform clouds as inferred from satellite microwave measurements. J. Geophys. Res., 95, 16 65916671.

_ D. Randall, and W. B. Rossow, 1996: Overview of Arctic cloud and radiation characteristics. J. Climate, 9, 1731-1764.

— cloudy boundary layer during the autumnal freezing of the Beaufort Sea. J. Geophys. Res., 102, 13 851-13 860.

Di Girolamo, L., and R. Davies, 1995: The image navigation cloud mask for the Multiangle Imaging Spectroradiometer (MISR). $J$. Atmos. Oceanic Technol., 12, 1215-1228.

Ebert, E. E., 1989: Analysis of polar clouds from satellite imagery using pattern recognition and a statistical cloud analysis scheme. J. Appl. Meteor., 28, 382-399.

Francis, J. A., 1994: Improvements to TOVS retrievals over sea ice and applications to estimating Arctic energy fluxes. J. Geophys. Res., 99, 10 395-10 408.

Gloersen, P., and W. J. Campbell, 1988: Satellite and aircraft passive microwave observations during the Marginal Ice Zone Experiment in 1984. J. Geophys. Res., 93, 6837-6846.

_, W. Nordberg, T. J. Schmugge, T. T. Wilheit, and W. J. Campbell, 1973: Microwave signatures of first-year and multiyear sea ice, J. Geophys. Res., 78, 3564-3572.

_ W. J. Campbell, D. J. Cavalieri, J. C. Comiso, C. L. Parkinson, and H. J. Zwally, 1992: Arctic and Antarctic sea ice, 1978-1987: Satellite passive-microwave observations and analysis. NASA SP-511, 290 pp.

Goodison, B. E., and D. Yang, 1996: In-situ measurement of solid precipitation in high latitudes: The need for correction. Proc. Workshop on the ACSYS Solid Precipitation Climatology Project, Reston, VA, WCRP-93, WMO/TD 739, 3-17.

Grody, N. C., 1993: Remote sensing of the atmosphere from satellites using microwave radiometry. Atmospheric Remote Sensing by Microwave Radiometry, M. A. Janssen, Ed., John Wiley and Sons, $572 \mathrm{pp}$.

Groves, D. G., 1999: A new moisture budget of the Arctic atmosphere derived from 19 years of daily TOVS satellite moisture retrievals and NCEP reanalysis winds. Preprints, Fifth Conf. on Polar Meteorology and Oceanography, Dallas, TX, Amer. Meteor. Soc., $107-112$.

Haggerty, J. A., and J. A. Curry, 2001: Variability of surface emissivity estimated by airborne passive microwave measurements during FIRE SHEBA. J. Geophys. Res., 106, 15 265-15 277.

Intrieri, J. M., M. D. Shupe, T. Uttal, and B. J. McCarty, 2002: An annual cycle of Arctic cloud characteristics observed by radar and lidar at SHEBA. J. Geophys. Res., in press.

Key, J. R., 1990: Cloud cover analysis with Arctic Advanced Very High Resolution Radiometer data. 2. Classification with spectral and textural measures. J. Geophys. Res., 95, 7661-7675.

_ 2000: The Cloud and Surface Parameter Retrieval (CASPR) system for polar AVHRR. Cooperative Institute for Meteorological Satellite Studies, University of Wisconsin-Madison, 59 pp.

and R. G. Barry, 1989: Cloud cover analysis with Arctic AVHRR data. 1. Cloud detection. J. Geophys. Res., 94, 85218535 .

Kummerow, C., W. S. Olson, and L. Giglo, 1996: A simplified scheme for obtaining precipitation and vertical hydrometeor profiles from passive microwave sensors. IEEE Trans. Geosci. Remote Sens., 34, 1213-1232.

Liljegren, J. C., 1994: Two-channel microwave radiometer for observations of total column precipitable water vapor and cloud liquid water path. Preprints, Fifth Symp. on Global Change Studies, Nashville, TN, Amer. Meteor. Soc., 262-269.

Liu, G., 1998: A fast and accurate model for microwave radiance calculations. J. Meteor. Soc. Japan, 76, 335-343.

_ , and J. A. Curry, 1996: Large-scale features during January 1993 in the North Atlantic Ocean as determined from SSM/I and SSM/T2 observations. J. Geophys. Res., 101, 7019-7032.

_ determined using satellite microwave data. J. Geophys. Res., 102, 13 987-13997.

Maslanik, J. A., C. Fowler, J. Heinriches, R. G. Barry, and W. G. Emery, 1995: Remotely sensed and simulated variability of Arctic sea ice condition in the response to atmospheric synoptic systems. Int. J. Remote Sens., 16, 33 325-33 342.

Mokhov, I. I., and M. E. Schlesinger, 1994: Analysis of global cloudiness. 2. Comparison of ISCCP, Meteor and Nimbus 7 satellite data. J. Geophys. Res., 99, 17 045-17 065.

Overland, J. E., and P. S. Guest, 1991: Arctic snow and air temperature budget over sea ice during winter. J. Geophys. Res., 96, 46514662.

Perovich, D. K., and Coauthors, 1999: Year on ice gives climate insights. Eos, Trans. Amer. Geophys. Union, 80, 481.

Petty, G. W., 1994: Physical retrievals of over-ocean rain rate from 
multichannel microwave imagery. Part II: Algorithm implementation. Meteor. Atmos. Phys., 54, 101-121.

Prigent, C., and W. B. Rossow, 1999: Retrieval of surface and atmospheric parameters over land from SSM/I: Potential and limitations. Quart. J. Roy. Meteor. Soc., 125, 2379-2400.

Ramanathan, V., R. D. Cess, E. F. Harrison, P. Minnis, B. R. Barkstrom, E. Ahmad, and D. Hartmann, 1989: Cloud-radiative forcing and climate: Results for the Earth Radiation Budget Experiment. Science, 243, 138-140.

Raschke, E., 1987: Rep. International Satellite Cloud Climatology Project (ISCCP) Workshop on Cloud Algorithms in the Polar Regions. WMO/TD 170, WMO, Geneva, Switzerland, 12 pp.

— - P. Bauer, and H. J. Lutz, 1992: Remote sensing of clouds and surface radiation budget over polar regions. Int. J. Remote Sens., 13, 13-22.

Rossow, W. B., and L. C. Garder, 1993: Validation of ISCCP cloud detections. J. Climate, 6, 2370-2393.

_ - A. W. Walker, and L. C. Garder, 1993: Comparison of ISCCP and other cloud amounts. J. Climate, 6, 2394-2418.

Schweiger, A. J., and J. R. Key, 1992: Arctic cloudiness: Comparison of ISCCP-C2 and Nimbus-7 satellite-derived cloud products with a surface-based cloud climatology. J. Climate, 5, 1514-1527.

Scott, N. A., and Coauthors, 1999: Characteristics of the TOVS Pathfinder Path-B dataset. Bull. Amer. Meteor. Soc., 80, 2679-2701.

Serreze, M. C., R. G. Barry, and J. E. Walsh, 1995: Atmospheric water vapor characteristics at $70^{\circ} \mathrm{N}$. J. Climate, 8, 719-731.

—_, F. Carsey, R. G. Barry, and J. C. Rogers, 1997: Icelandic low cyclone activity: Climatological features, linkages with the NAO, and its relationships with recent changes in the Northern Hemisphere circulation. J. Climate, 10, 453-464.

Smith, E. A., X. Xiang, A. Mugnai, and G. J. Tripoli, 1994: Design of an inversion-based precipitation profile retrieval algorithm using an explicit cloud model for initial guess microphysics. Meteor. Atmos. Phys., 54, 53-78.

Stubenrauch, C. J., W. B. Rossow, F. Cheruy, A. Chedin, and N. A. Scott, 1999a: Clouds as seen by satellite sounders (3I) and imagers (ISCCP). Part I: Evaluation of cloud parameters. J. Climate, 12, 2189-2213.

—_, A. Chédin, R. Armante, and N. A. Scott, 1999b: Clouds as seen by satellite sounders (3I) and imagers (ISCCP). Part II: A new approach for cloud parameter determination in the $3 \mathrm{I}$ algorithms. J. Climate, 12, 2214-2223.

Thompson, D. W. J., and J. M. Wallace, 1998: The Arctic Oscillation signature in wintertime geopotential height and temperature fields. Geophys. Res. Lett., 25, 1297-1300.

Ulaby, F. T., R. K. Moore, and A. K. Fung, 1981: From Theory to Applications. Vol. III, Microwave Remote Sensing: Active and Passive, Artech House, 1120 pp.

Walsh, J. E., and D. H. Portis, 1999: Relationship between the atmospheric circulation of the central Arctic and the North Atlantic. Preprints, Fifth Conf. on Polar Meteorology and Oceanography, Dallas, TX, Amer. Meteor. Soc., 1-4.

Welch, R. M., S. K. Sengupta, A. K. Goroch, P. Rabindra, N. Rangaraj, and M. S. Navar, 1992: Polar cloud and surface classification using AVHRR imagery: An intercomparison of methods. J. Appl. Meteor., 31, 405-420.

Wilheit, T. T., A. T. C. Chang, M. S. V. Rao, E. B. Rodgers, and J. S. Theon, 1977: A satellite technique for quantitative mapping rainfall rates over the oceans. J. Appl. Meteor., 16, 551-560.

Yamanouchi, T., and S. Kawaguchi, 1992: Cloud distribution in the Antarctic from AVHRR data and radiation measurements at the surface. Int. J. Remote Sens., 13, 111-127.

Zuidema, P., and D. L. Hartmann, 1995: Satellite determination of stratus cloud microphysical properties. J. Climate, 8, 1638-1657. 
Copyright $\odot 2003$ EBSCO Publishing 